\title{
Entre el español y el zoque: la poesía y la traducción en Mikeas Sánchez frente a la violencia contra las mujeres y la cultura
}

\author{
Violeta Percia \\ violeta.percia@gmail.com \\ https://orcid.org/0000-0002-6697-0136 \\ Instituto de Filología y Literaturas Hispánicas, Facultad de Filosofía y Letras, \\ Universidad de Buenos Aires, Argentina
}

\section{Resumen}

En su libro Mojk'jäyä Mokaya (2013), Mikeas Sánchez muestra la violencia discursiva que recae sobre la condición de ser mujer y ser indígena. Se trata de una doble dominación, inscripta en el cuerpo de la palabra y en el lugar de la traducción: como indígena, la violencia de haber sido nombrada en el español hegemónico del México mestizo y criollo; como mujer, determinada por las miradas, los deseos y los cuerpos de los hombres. Frente a eso, la poeta recupera la visión de mundo zoque, para resignificar el lugar de las mujeres, mediante el aporte de un pensamiento sobre la traducción que trabaja en la conciencia de que "nombrar las cosas" es darse un cuerpo y reconocerse un origen pronunciados contra la dominación ejercida por la palabra del otro. Así, en el marco de los estudios poscoloniales que han evidenciado la dependencia intelectual y epistémica que existe aún hoy en la teoría latinoamericana, este trabajo aborda la praxis traductora como un lugar privilegiado para intervenir sobre los dispositivos coloniales que pesan sobre la cultura y lengua.

Palabras clave: Poesía en lenguas indígenas, estudios de traducción, autotraducción, estudios poscoloniales, interculturalismo, Mikeas Sánchez.

\section{Between Spanish and Zoque: Poetry and Translation in Mikeas Sánchez Faced With Violence Against Women and Culture}

\begin{abstract}
In her book Mojk'jäyä Mokaya (2013), Mikeas Sánchez shows the discursive violence that affects the condition of being a woman and indigenous. It is a double domination inscribed in the body and speech and in the space of the translation: as indigenous, the violence of having been named in the hegemonic Spanish of the mestizo and criollo Mexico; as a woman, limited by the looks, the desires and bodies of men. Before that reality, the poet recovers the vision of the zoque world to resignify the role of women, presenting an idea of translation that works on the awareness of the fact that "naming things" is to give oneself a body and to recognize an origin, pronounced against the domination exercised by the word of the others. Within the framework of the postcolonial studies that have evidenced the intellectual and epistemic dependence that still exists in Latin American theory, this
\end{abstract}


work attempts to approach the translation praxis as a privileged space to intervene on the colonial mechanisms that impact on the culture and language.

Keywords: poetry in indigenous language, translation studies, self-translation, postcolonial studies, Mikeas Sánchez, interculturalism.

Entre l'espagnol et le zoque : la poésie et la traduction chez Mikeas Sánchez face à la violence contre les femmes et la culture

\section{Résumé}

Dans son livre, Mojk'jäyä Mokaya (2013), Mikeas Sánchez montre la violence discursive qui affecte la condition d'être une femme et d'être indigène. C'est une domination double, inscrite dans le corps de la parole et dans l'espace de la traduction : en tant qu'indigène, la violence d'avoir été nommée en l'espagnol hégémonique du Mexique mestizo et criollo; en tant que femme, définie par les regards, les désirs et les corps des hommes. Face à cette réalité, la poétesse reprend la vision du monde zoque pour resignifier le lieu des femmes, en apportant une idée sur la traduction qui sensibilise à " nommer les choses " pour se donner un corps à soi-même et reconnaître une origine, en se prononçant contre la domination exercée par les mots des autres. Ainsi, dans le cadre des études postcoloniales, qui ont mis en évidence la dépendance intellectuelle et épistémique qui existe toujours dans la théorie latino-américaine, ce travail aborde la praxis de la traduction comme un lieu privilégié pour l'intervention des mécanismes coloniaux qui pèsent sur la culture et la langue.

Mots-clés : poésie en langues indigènes ; traductologie ; auto-traduction ; études postcoloniales ; interculturalisme ; Mikeas Sánchez. 


\section{0}

\section{Introducción}

Desde el último tercio del siglo xx hasta esta segunda década del XXI viene desarrollándose, en el marco de la poesía contemporánea, un interesante movimiento de poesía en lenguas indígenas, que se concibe, más allá de las fronteras nacionales, como un espacio de resistencia de la palabra, pero también de los territorios, las lenguas, los pensamientos, los saberes y la memoria de los pueblos, dando cuenta de un proceso que se consolida como uno de los hechos culturales más relevantes del continente americano. Se inscriben allí escritores y escritoras que mantienen diálogos diversos con su propia ancestralidad (viviendo dentro de sus comunidades y en el ámbito de las tradiciones de sus antiguos, o atravesados por realidades migrantes y urbanas), que trazan modos precisos de visibilidad y revalorización de enclaves hermenéuticos propios a sus culturas. Así, desde la perspectiva del diálogo intercultural, estas poéticas pueden considerarse como un lugar privilegiado de la conversación y la traducción entre lenguas, y, por tanto, un ámbito esencial para entender la necesidad de situar las formas de una alteridad epistémica.

Se trata de producciones poéticas que cruzan dos o más universos socioculturales; que conforman un sistema literario, caracterizado por determinadas apropiaciones de la palabra hablada en el seno de un discurso letrado; que asumen el problema del interlingüismo o multilingüismo, la pluriculturalidad y que, en particular, se enfrentan a fenómenos de heteroglosia (que exigen estudiar la interrelación y convergencia de diferentes expresiones literarias, pero también de significantes de distintos idiomas, dialectos y registros), modalidades donde, como señala Mabel Moraña, "se expresan proyectos divergentes e irreconciliables relaciones de poder, en las que se revelan las negociaciones que se operan en la pugna de diversos sujetos o sectores sociales por el derecho o el privilegio representacional" (2013, p. 9). El texto poético o cultural se concibe, así, como un espacio simbólico de esas tensiones, que pueden explorarse a la manera de territorios, o también como zonas fronterizas y de contacto, donde se plasman las disputas que atraviesan los distintos proyectos culturales, sus metáforas y sus imaginarios.

Este artículo indaga dichas problemáticas, a partir del análisis de la operación de traducción que la poeta zoque Mikeas Sánchez realiza en su libro Mojk'jäyä Mokaya, edición bilingüe zoque-español, donde emprende un proceso de autotraducción que se mueve en el doble espacio de la lengua y la cultura. Allí, la autora muestra la importancia del acto de traducción como un modo de recuperación y reapropiación de la palabra frente a la violencia discursiva que recae sobre la condición de ser mujer y ser indígena. Contra esa doble dominación inscripta en el cuerpo de la lengua, la poeta recupera la visión de mundo zoque para, desde allí, resignificar el lugar de las mujeres, aportando un pensamiento sobre la traducción que trabaja en la conciencia de que nombrar las cosas es darse una identidad y reconocer un origen, pronunciados contra la dominación ejercida por la palabra del otro.

Sin ignorar las discusiones teóricas que existen en torno a conceptos y perspectivas críticas que se abordan en este trabajo (tales como autotraducción, bilingüismo, heteroglosia, o más ampliamente las problemáticas interculturales y los diferentes dispositivos coloniales que operan múltiples violencias simbólicas sobre los cuerpos de las minorías culturales -en el orden de los significantes y del valor significante de los cuerpos)-, ni olvidar las perspectivas feministas que vienen trabajando en estos sentidos, este estudio sienta posición sobre algunos de dichos aspectos, pero se cen- 
tra fundamentalmente en el análisis del último poemario de Sánchez, pensado como espacio de reflexión sobre la práctica traductora que se inscribe en esa doble encrucijada de traducir lengua y cultura, y, más específicamente, de (auto)traducirse en (y desde) un mundo escindido, fronterizo, cambiante, reclamando y reivindicando la identidad y las raíces indígenas. Se trata, entonces, de reflexionar sobre la práctica traductora y poética de Mikeas, en cuanto forma de situar esa diferencia cultural y gnoseológica, $\mathrm{y}$, finalmente, como espacio posible de apertura a discusiones futuras sobre la traducción.

\section{La poesía de Mikeas Sánchez como práctica de traducción}

Nacida en Tujsübajk (Río de aguas verdes), Chapultenango, Chiapas, Sánchez es poeta y narradora zoque, magíster en Didáctica de la Lengua y la Literatura por la Universidad Autónoma de Barcelona, y desarrolla, además, una tarea como activista por los derechos de la tierra. ${ }^{1}$ Si bien era una lengua extranjera en su propia nación, en su propia tierra, el español se le impuso en la escritura cuando ingresa al sistema escolar. Ella misma se refiere a este proceso y choque cultural en diversas entrevistas, dando testimonio de la compleja situación de la educación bilingüe en México y de la demora que lenguas como el zoque padecen, debido a políticas lingüísticas defectuosas para la implementación de una enseñanza verdaderamente intercultural, que no use la lengua indígena solo como vehículo oral para enseñar el español, sino que, además, les confiera a sus hablantes un dominio pleno de su escritura. ${ }^{2}$

1 Mikeas forma parte activa del Movimiento Indígena del Pueblo Creyente Zoque en Defensa de la Vida y de la Tierra (Zodevite).

2 Véase Carballo (2012).
Precisamente, en esa tensión entre oralidad y escritura, característica de los dispositivos coloniales, la poeta advierte que conservar las lenguas maternas es la mejor defensa del territorio, por lo que adopta la posición ética y política de escribir de manera bilingüe ore-español. ${ }^{3}$ En efecto, la usurpación del territorio y la pérdida de la lengua son dos condiciones que se hallan unidas. De ahí que la defensa de los territorios resulte consecuente de una valoración de la lengua que los habla, en la medida en que la comprensión de la vida misma de los territorios se origina en imágenes de lengua, en sus palabras poéticas y metáforas, que son también palabras conocedoras o pensantes. Por ese motivo, concebido como enclave bilingüe, el poema supone, en su límite, un desafío de traducción en el cual reside la posibilidad de plasmar un pensamiento de raíces indígenas que asuma, en este continente, no solo un diálogo intercultural, sino también su diferencia epistémica. ${ }^{4}$

3 El idioma ore o zoque del norte alto es una de las ocho variantes del zoque; pertenece al tronco de lenguas otomangue (como la me'phàà o tlapaneco), y más específicamente a la rama zoqueana del mixe-zoque. Se asienta históricamente en los estados de Chiapas y Oaxaca, en México.

4 Por "diferencia epistémica" nos referimos tanto a una hermenéutica propia, es decir, a una forma específica de entender e interpretar el mundo y la existencia, como a una manera de acceder al conocimiento, el cual implica modos otros de fundarlo, validarlo y legitimarlo. Una de las intelectuales que aborda esta cuestión más lúcidamente es Silvia Rivera Cusicanqui (2018), quien ha remarcado el hecho de que para reconocer cabalmente la diferencia cultural del continente americano y ejercer una valorización de los conocimientos y las voces indígenas que los mueven, resulta fundamental entender, ante todo, que lo que determina esa diferencia es de orden epistemológico. Pensar lo indígena en su singularidad epistémica implica, entonces, abrirse a otros criterios gnoseológicos, a otra comprensión de los cuerpos y, en definitiva, a formas discursivas, usos de la palabra y praxis comunitarias que no solo son distintas, sino que también tienen mucho que enseñar a las sociedades contemporáneas, 
Hay que notar que la poesía contemporánea amerindia generalmente se concibe como texto bilingüe, en el cual el autor o la autora afrontan un proceso de autotraducción o reescritura, ya sea que escriban primero en su lengua materna y piensen luego la versión en español, o viceversa, e incluso que conciban el poema a través de las dos lenguas, es decir: como un género que se va entre-tejiendo en el hilo de ambos idiomas, que va apareciendo en esa juntura; un texto que no está absolutamente ni en una lengua ni en la otra, sino en ese hiato entre ambas, en los encuentros entre palabras e imágenes que allí se propician, como una suerte de poesía a dos voces. La reflexión sobre los desafíos tanto de escritura como de traducción que esta poesía enfrenta en el texto bilingüe puede significar, por tanto, un aporte para los estudios de traducción, en cuanto pone de relieve, a su vez, la necesidad de reconocer la singularidad hermenéutica del universo del que afloran los conocimientos indígenas y precisa posibles abordajes metodológicos a esos textos. Porque, como dice Bárbara Cassin, "los caminos de la traducción [...] son caminos de poder" (2019, p. 60), por lo cual son canales tanto de dominación como instancias de posibilidad y oportunidad para la escucha, el diálogo y el aprendizaje.

Como se sabe, desde el último tercio del siglo xx, el campo de los estudios culturales y la sociología vienen poniendo de relieve la exigencia de comprender la heterogeneidad plurilingüe e intercultural del continente, y la urgencia de una revisión y transformación de ciertas categorías o paradigmas del pensamiento moderno

cuyos modos de producción y explotación, de justicia, de democracia han demostrado su fracaso. Rivera Cusicanqui ha abierto así una interesante vía crítica de muchas de las teorías poscoloniales, cuyo límite reside, según ella, justamente, en su imposibilidad de dar el salto hacia la comprensión de estas diferencias epistémicas. occidental, que han conducido a catástrofes ecológicas, económicas, sociales y políticas. En este marco, advertimos la necesidad de pensar, además, una constelación crítica que permita trazar una topología de la palabra poética, allí donde la misma se abre precisamente a otra visión de mundo; donde se hace sensible a una rica herencia, que tiene mucho que enseñar al naufragio de la razón normativa de Occidente. Bajo estas condiciones, si la reflexión y la práctica de la traducción ocuparon un lugar ineludible en la mayoría de los teóricos y teóricas del siglo pasado, las mismas adquieren, en la actualidad, un rol fundamental a la luz de las realidades pluriculturales y migrantes en el mundo entero. En este ámbito se destacan especialmente los aportes actuales de la traductología feminista, en función de la construcción de perspectivas críticas y teóricas plurales, transfronterizas e inclusivas. ${ }^{5}$

Por tal motivo, el texto bilingüe cobra un valor esencial en estas distribuciones de sentido, ya que permite reterritorializar las lenguas indígenas, pero al mismo tiempo propone un proceso de desterritorialización del español -que implica, de alguna manera, sacarlo de su supremacía colonial, para reinscribirlo en el seno de su propia heterogeneidad cultural latinoamericana-.

Por otra parte, aun cuando no podamos leer las dos lenguas y comparar las traducciones, este dispositivo bilingüe resulta fundamental para comprender que el español no representa ni posee $e l$ logos -única razón, garantía de la ley y ley del discurso-, sino que debe reconocerse como "una lengua entre otras" (Cassin, 2019, p. 94); más aún, es una lengua que crece en los

5 Para un estado de la trayectoria de las perspectivas feministas de y sobre la traducción, remitimos al trabajo de Castro y Spoturno (2020). 
territorios indígenas y en el contacto con sus idiomas originarios.

$\mathrm{Al}$ escribir en las dos lenguas, la negociación traductológica se realiza desde la vivencia cultural de los dos mundos que le son propios al autor o la autora. La autotraducción surge, entonces, como una necesidad. Es un modo de pensar en los dos idiomas, pero también de elegir qué se le dice a cada uno. Se escribe en español para poder dirigirse a un campo de la palabra transfronterizo. Se escribe en zoque (en el caso de Mikeas) para poder revalorizar la propia lengua, defender sus territorios de sentidos, abrir un espacio para la producción de una escritura en ese idioma.

Por otra parte, la autotraducción podría considerarse dentro de un proceso de re-traducción, en el cual se distinguen al menos dos espacios y dos tiempos de traducción, que habilitan una reflexión sobre aquello que Antoine Berman llamó la "temporalidad del traducir" (temporalité du traduire), que ponen en juego el vínculo que establece el traductor con más de un texto (en el caso de Mikeas, la versión en ore y la versión en español) y permiten indagar de qué modo madura la relación entre esas lenguas, maduración que consiste en aceptar la "conmoción" de una lengua en la otra: asumir sus formas, sus modos de decir (Berman, 1999, pp. 104-106).

De esta manera, publicado en 2013, en México, por la editorial Pluralia, el quinto poemario de Mikeas Sánchez, Mojk'jäyä Mokaya, se concibe en este marco como un texto bilingüe. ${ }^{6}$ Hay que observar, no obstante, que las versiones en español se presentan como un tejido donde el ore

6 Sánchez había publicado anteriormente Maka mujsi tumä jama / Y sabrás un día (2006); Äj' ngujkomo / Desde mi médula (2011); Kobikyajubäjaye / Selección poética (2012a) y Mumure' tä' yäjktambä / Todos somos cimarrones (2012b). está también presente, insistiendo mediante algunas palabras que no pueden ser traducidas -algo que Iván Carrasco llamó collage lingüistico o texto de doble registro, para referirse a una codificación plural o heteroglósica del escrito (2000, p. 197)—. Aquí, la traducción visibili$\mathrm{za}$, en realidad, una zona intraducible que, por normativas editoriales, aparece señalada en bastardilla, a pesar de que dicho recurso lo que hace es reforzar la extranjería de esos términos, expulsándolos de alguna manera del texto, o por lo menos tiñéndolos de un extrañamiento.

De este modo, en las palabras de la otra lengua que persisten en el poema traducido se abre una dimensión para la que no hay traducción, porque en ella insiste una singularidad, un pensamiento que quiere ser pensado, y que sale a la luz por la experiencia poético-filosófica del otro idioma - como dice Cassin, "son las huellas dactilares de la lengua" (2019, p. 21), "los sintomas de diferencia entre lenguas” (Cassin, 2019, p. 109)-.

Hay que entender bien, en este punto, que lo intraducible no es lo que no se traduce, ni mucho menos algo que no puede traducirse, por lo cual no remite a una esencia ontológica de lo significante. Antes bien, se trata, siguiendo a Cassin, de "lo que no cesa de (no) traducirse" (2019, p. 21). De un resto, que se escapa o se sustrae a una única traducción. Reside allí aquello que continúa traduciéndose con cada traducción, que exige ser pensado desde una lengua en otras y, finalmente, aquello que permite pensar entre lenguas, que es anterior al lenguaje, no por ser inteligible en un plano de las ideas, sino porque implica el hiato entre lo semiótico y lo semántico. ${ }^{7}$ Son también palabras intraducibles

\footnotetext{
7 Seguimos aquí al horizonte conceptual que traza el filósofo Giorgio Agamben cuando considera la anterioridad del lenguaje como un lugar anterior al sentido, el lugar de una experiencia que en sí misma no tiene significado ni es
} 
que persisten como tales, porque incorporan nuevos sentidos, simultáneos, contradictorios - significantes para un pensamiento que no conoce sin palabras, que las necesita para comprender lo que antes no veía-.

Finalmente, en esos intraducibles surge la posibilidad de posicionar la diferencia de las lenguas, en función de términos que comportan, ellos mismos, una importancia y un valor epistémicos. Se trata de aquello que el francés Jacques Derrida (1985) comprendió cuando definió la traducción como el gesto filosófico por excelencia, en la medida en que trabaja en un límite entre lenguas que hace posible el pensar. Para él, el pensamiento nace entre lenguas, porque lo que se piensa en ellas tiene lugar en ese término del lenguaje que pide una traducción - que exige forzar los sentidos de la propia lengua en la lengua del otro-. En efecto, el pensar comienza en el límite de la palabra, en sus con-fines, en la experiencia, allí donde se origina y encuentra sus limitaciones, donde adquiere sentido y halla también su contradicción. La traducción es la experiencia de pensar con la lengua, de preguntarse cómo piensa la lengua, pero también de ver lo que se piensa en ella.

Hay, en el poemario de Mikeas, una primera cosa que permanece intraducida: el título, él mismo, entonces, un intraducible. Desde el nombre Mojk'jäyä Mokaya, el libro se inscribe de manera radical en la cultura zoque - en un mundo que, en su diferencia, requiere traducciones, pero que no admite la transparencia de las lenguas, que no consiente el borramiento de su diferencia-. A su vez, por allí se sitúa en la concepción de una doble presencia, masculina y femenina, inscripta en la palabra mokaya,

significante, pero se vuelve significante en un encuentro (o choque) entre lo semiótico y lo semántico (Agamben, 2004, p. 64). cuya raíz etimológica mojk, en lengua ore, se traduce como "maíz". De hecho, mokaya es también "quien cultiva el maíz", "el hombre de maíz" (y quien como sustentador y sustento le da un sentido de comunidad al pueblo); pero esta palabra deriva de mojk'jäyä, que es la "mujer de la flor de maíz" (también sustento y sustentadora de los frutos que definen el espacio comunitario-alimentario del mundo zoque). Uno y otra están determinados, de esa forma, por una permanente correspondencia, colaboración y reciprocidad de sentidos comunitarios que se despliegan en torno al alimento y al trabajo de la tierra. El grano y la flor son parte del mismo proceso de construcción de sentidos, que provienen de esa misma raíz de la lengua, de la misma planta que es el maíz, y que existe gracias a esa conspiración (de lo que respira en común) y a esa comunión (de lo que se tiene y se aguarda en común).

En efecto, Mojk'jäyä Mokaya resuena como un eco, una palabra (Mojk'jäyä) que se repite en otra (Mokaya), que no es su homónima, sino su contemporánea, pero juntas crean una homonimia del sentido que no puede trasladarse sin recurrir a una nota de traducción, pues existe una reciprocidad de una y de otra que se conserva en las metáforas de la lengua. Con "homonimia" se alude aquí a un sentido disperso que se multiplica en sus imágenes poéticas, en sus componentes metafóricos, en sus sinsentidos; que hace sentido en sus contradicciones, pero también en sus usos dentro de una tradición. ${ }^{8}$

8 Seguimos, asimismo, en este punto a Bárbara Cassin (2019, pp. 85-86), quien desarrolla una teoría de la anfibología y la homonimia para referirse a esos casos en que las palabras tomadas no solo una por una, sino juntas, en una frase, texto o contexto, forman combinatorias dotadas de sentido (muchas veces de equívocos, paradojas y contradicciones); en este tipo de expresiones reside, para la autora, la esencia pensante de la lengua, pero también las dificultades de la traducción. 
Pensado a partir de este significante de la lengua ore, el texto de Sánchez se va a construir sobre una dualidad de mundos o de tiempos, entendida entonces no en la medida de algo que separa, escinde, confronta y debe ser superado (dominado) en términos dialécticos, sino de aquello cuya naturaleza misma es la conciliación, la contigüidad; dos sentidos que colaboran juntos y se continúan el uno en el otro, en un tiempo que ya fue y que no ha sido todavía; dos sentidos que se reconocen en el encuentro, en el lazo, donde no es posible ver en qué punto empieza o termina cada uno de los términos.

Presente en el mundo zoque desde la lengua, esta idea de dos estados entendidos desde la reciprocidad interesa para el pensamiento de la traducción, porque precisamente la relación entre dos es fundacional de esta práctica, que históricamente se ha concebido como un enfrentamiento de enunciados o de textos jerárquicamente desiguales, vinculados en términos de una subordinación: la traducción siempre depositaria del original, segunda con relación a él, e inferior por no ser capaz de alcanzar el acabamiento y la plenitud del original, el cual se convierte en la medida. En efecto, a lo largo de la historia, ese vínculo entre dos ha sido sostenido con diferentes metáforas e imágenes que muestran esta jerarquización: la idea de la copia, del calco, de la costilla de Adán. De modo que Occidente ha dado a esa analogía la forma de una herida, de una inautenticidad, de una violencia primitiva y de una negación. ${ }^{9}$

9 Existe una teoría de traducción que ha abordado esta problemática en clave feminista; es el caso, entre otras, de teóricas como Barbara Godard, Luise van Flotow, Sherry Simon o Susanne de Lotbinière-Harwood (véase, en especial, De Lotbinière-Harwood, 1991). Partimos, sin embargo, aquí, de los ensayos sobre traducción del argentino Santiago Perednik (2012), donde el autor sostiene que pese a las diversas y múltiples perspectivas desde las que históricamente se encara la teoría de la
La concepción zoque de la dualidad como continuidad y alianza (abiertas) en la diferencia, presente en el sintagma Mojk'jäyä Mokaya, permite, en cambio, pensar la traducción desde un ángulo distinto al instaurado tanto por las lógicas dialécticas como por las disciplinarias o esencialistas forjadas por las filosofías modernas de la alteridad en Occidente, dentro de las que se ha moldeado la teoría de la traducción. Por el contrario, la noción con la que trabaja Sánchez hace posible establecer una relación de encuentro, de necesidad y correspondencia entre las lenguas, que se traducen en el sentido del cuidado y el don entre los mundos que se encuentran, se resquebrajan y se componen de una lengua a la otra.

En este contexto, el libro de la poeta zoque pone en acto ese vínculo entre dos en múltiples planos, en la medida en que se mueve permanentemente en los niveles de la lengua y de la cultura - en la relación entre el cuerpo y la lengua, entre el territorio y la palabra-. Y lo hace problematizando al mismo tiempo, por un lado, la dimensión de la violencia cultural

traducción, la mayoría de ellas han insistido en tres características comunes: la aritmética del dos, el vínculo moral y el conflicto. El primer problema de este paradigma surge al considerar la traducción como una situación entre dos elementos, el "original" y la "versión", anudados en el marco de una lógica binaria a partir de la cual esta pareja se multiplica en nuevas parejas (el autor y el traductor; la lengua del original y la de la versión; las culturas, las literaturas, las coyunturas históricas a las que uno y otro pertenecen). Pero, sobre todo, el problema reside en que ese vínculo se estructura sobre una desigualdad constitutiva (en tanto se asigna a uno de ellos un lugar privilegiado, y al otro, uno de subordinación). De manera tal que esta relación se piensa desde el comienzo en los términos de un conflicto al que se le confiere un carácter moral, siguiendo el modelo de las relaciones humanas, en la forma de la fidelidad, la autoridad o la jerarquía de valores, literarios y estéticos. Sobre el problema del original en la traducción poética, remitimos también a nuestro artículo (Percia, 2017). 
del México mestizo y criollo sobre los mundos indígenas, y con ello, la violencia simbólica y real de la lengua del Estado sobre las lenguas minorizadas; y, por otro, la violencia del lenguaje de los hombres, de sus cuerpos y sus deseos sobre el cuerpo y la palabra de las mujeres. Así, si la traducción se teoriza a partir de una relación de subordinación al original, aquí se denuncia una doble imposición de inferioridad y subordinación discursiva: la de ser mujer e indígena.

La opresión cultural sobre las mujeres, que se reproduce en un mundo zoque contemporáneo atravesado por la sociedad moderna $\mathrm{y}$ mestiza, redobla la destitución por ser indígenas que sufre todo el pueblo zoque en su conjunto. ${ }^{10}$ Son los signos, en palabras de la poeta mapuche Liliana Ancalao, de una "política de avergonzamiento" (2004, p. 8) que se ha ejercido en la lengua, convirtiéndola en un estigma, y que ha transformado, de ese modo, la herencia indígena y el origen en una marca de inferioridad, obligando por la fuerza a abandonarlos y que ocasiona, como consecuencia, una falta de autoestima lacerante. La violencia de la lengua (desde ella y sobre ella) es la violencia de una cultura y de un poder colonial sobre los cuerpos, sobre los territorios y sobre las formas de pensar y comprender al otro. Se trata de esa violencia que proviene no

10 Hay que recordar un poco el contexto de muchas de las naciones indígenas de la zona de Chiapas en México, que se destapa con la revolución zapatista de las mujeres, que puso en juego el hecho de que no podían estudiar, ni acceder a la herencia de la tierra, ni tenían parte en muchas de las decisiones familiares y comunitarias (condiciones que se profundizan en el choque cultural y la formación de los Estados modernos, con sus lógicas individualistas de acumulación y explotación de la tierra, que se imponen sobre las lógicas comunitarias indígenas). Al respecto, véase el documental de Adriana Estrada, Tierra de mujeres (2003). Para un estudio de los feminismos en México remitimos a Millán (2009). de lo que la lengua impide decir, sino de lo que obliga a decir (Barthès, 1993, p. 120): de una imposición de significantes. De ese modo, la lengua es lugar de identidad, pero antes de una batalla por los sentidos que exige traducir el lenguaje de la violencia desde una perspectiva tanto indígena como de género.

Frente a estas realidades que el libro evidencia y confronta, Sánchez realiza dos movimientos de restitución y recuperación de la palabra: primero, toma posición desde la visión de mundo zoque que ella ha heredado, para redefinir, a partir de allí, el lugar de la mujer, aportando un pensamiento sobre la traducción que trabaja en la conciencia de que "nombrar las cosas" (wejpäj'kiu'y) es darse un cuerpo y es reconocerse un origen, pronunciados contra la violencia ejercida por la palabra del otro (una palabra unidireccional, absoluta, omnipotente y omnipresente). ${ }^{11} \mathrm{Y}$ segundo, restituye entonces el valor de la cultura zoque, reinscribiéndola en la alegría, el abrigo y la historia de su lengua - en su herencia y sus sentidos-, devolviéndole su fuerza cognitiva, para cuestionar, a través de la visión de mundo zoque, la violencia de los hombres, y reparar la herida de las mujeres.

11 Así, en el poema seis de la sección “Wejpäj'kiu’y / Nombrar las cosas", se lee: "Sentado bajo la ceiba más colosal / árbol protector de voces antiguas / el sembrador apaga su silencio / Ahí Dios susurra a su oído / esa palabra invocada / lenguaje secreto de los peces / las plantas / y los animales pequeños" (Sánchez, 2013, p. 55). Y desde ese lenguaje secreto, el yo poético va a decir: "Me nombro y hablo por todas las niñas maltratadas" (p. 75), "Me nombro y hablo por todas las mujeres" (p. 89), "Celebro mi sexo / y las exquisitas formas de mis caderas [...] / glorifico mi alma / lo mismo que mis labios mayores y menores" (p. 101), para finalmente exclamar la soberanía de los nombres en uno de los versos del último poema que cierra el libro, donde se exclama: "No quiero que nadie más me nombre $[. .$. / Porque mi alma es inmortal [...] / y mi eternidad no tiene medida” (p. 103). 


\section{La poesía y la traducción como formas de restitución y reapropiación de la propia cultura}

El poemario de Sánchez está estructurado en lo que podríamos pensar como un poema-prólogo, "Oko'chuwe", y cuatro capítulos, que llevan los siguientes títulos: "Ore'yomo" (mujer zoque); "Mokaya" (maíz, protector de esta tierra); "Wejpäj'kiu'y / Nombrar las cosas", único apartado traducido; y "Mojk'jäyä" (flor del maíz). Los poemas de cada sección están, por su parte, numerados.

Resulta interesante que el nombre de las cosas se sitúe en el medio de esa diferencia masculina y femenina, marcando una herida de sutiles violencias, pero también el anhelo de recuperar la propia lengua. De hecho, los apartados que remiten a la mujer y a las palabras prologan el círculo protector-protectora de las cosechas, que se corresponde en el ciclo sembrar-florecer-cultivar de la flor-semilla, ligado al trabajo agrario. La lengua y la mujer son, en parte, gestadoras del sentido comunitario, son conservadoras, cuidadoras, portadoras de la memoria tanto de los nombres (del saber y de la historia) como de la tierra y de lo que nace.

Existe, entonces, una fuerte concepción del libro como totalidad, cuya organización permite resignificar los textos en función del conjunto, a la luz del diálogo que trazan entre ellos y a partir de los títulos que llevan los apartados que los agrupan. Al mismo tiempo, esta estructura confiere una eficacia al libro, para interpelar a los lectores y las lectoras respecto del doble sentido de la violencia y minorización que la lengua dominante (patriarcal y colonial) ejerce sobre la cultura zoque y sobre las mujeres.

En esta dirección, el poemario adquiere la forma de una interpelación, o más bien de un llamado, que cobra magnitud al exponer diversas dimensiones del desprecio sufrido por ser mujer y por ser indígena, pero también al evocar las fuerzas y los privilegios de una herencia indígena viva a través de prácticas y saberes antiguos de la cultura y la tradición zoque, como las recuerda Mikeas.

El libro se dirige, entonces, a quien oye, lo compromete, lo aproxima a la intimidad de lo que pasa, pero también le destina una proclama, instándolo a asimilar sentidos de justicia y restitución con los que los poemas trabajan al inscribirse en las prácticas y los conocimientos de los antiguos zoque. De esa forma, la voz poética se concibe, en cierto modo, como una voz visionaria, que conoce lo que pasa, lo que duele, lo que atraviesa a las generaciones, que sabe los olvidos forzados y, asimismo, lo que resiste de una práctica y una herencia epistémica ancestral; a la vez que exhorta a la recuperación de lo sustraído, a la revisión de los errores, a la reparación de los daños.

En el primer capítulo, "Ore' yomo", se traza una continuidad de las heridas, a través de las generaciones, entre las violencias familiares y comunitarias, dando cuenta de una génesis de filiaciones lastimadas: desde una niña no querida por su padre, a una abuela casi niña deseada por un hombre (el abuelo), hasta llegar a la transformación de esos mandatos mediante la enseñanza a los propios hijos.

En esa primera sección se agrupan poemas que evocan la historia de la que ha nacido mujer, que fue una "niña parida con miedo" (Sánchez, 2013, p. 12), "Niña de pies descalzos" (p. 12), aquella "no deseada" (p. 12) porque "tu padre prefirió niño" (p. 12). Esa muchacha que llora porque desconoce su origen (p. 15), pero a la cual la voz poética invita a cantar y a sublimar el dolor juntas, a conocer que la fuerza proviene de una "diosa milenaria" (p. 15), mujer, 
que incluso los niños son fuertes porque tienen un "nahual [...] femenino" (p. 21). Así, el yo lírico se hermana y abraza a aquella niña que ha sufrido el destrato; más aún, le insufla en el aliento poético el pensamiento fuerte de quien se re-conoce como mujer zoque (ore'yomo), para pedirle a la gran abuela, madre que habita el mundo de los espíritus, "Acuérdate de mí cuando llegue a tu casa” (p. 18).

En la segunda sección, titulada "Mokaya", Mikeas inscribe esa fuerza femenina en la historia oral de su pueblo, en las praxis y los saberes del mundo zoque antiguo, un mundo ligado a la identidad agraria, al territorio y a la cosecha del maíz. De ese modo, el sembrador, el hombre maíz, el grano, representan la herencia como alimento y práctica que sustentan la vida ore. ${ }^{12}$ En este marco, la poeta revaloriza la Danza de la siembra, de los sembradores, tradiciones que tienen que ver con una alianza y colaboración de (la) comunidad con la Madre Tierra, del campesino con su milpa, de la semilla con la flor que le da origen, del hombre y la mujer con los modos de sustentar, concebir e imaginar la vida compartida.

En el capítulo siguiente, “Wejpäj'kiu'y / Nombrar las cosas", el mundo zoque es restituido a los territorios de su lengua: "mis palabras/ única herencia mi linaje" (Sánchez, 2013, p. 47). En ese territorio de sentidos se evocan las danzas tradicionales del sembrador (p. 44), el árbol sagrado de la Ceiba (p. 55); el “Tzuan'/nuestra herencia de nagual" (p. 57); es decir, todo ese suelo donde se entabla y practica un diálogo permanente con los protectores y dueños

12 En el poema siete del apartado "Mokaya", se lee: "Soy el sembrador / protector de esta tierra / la flor del maíz / observo con mis ojos antiguos / elijo con el corazón cada semilla" ("Äjte'te’dzundy / mokaya' / mojk'jäyä / Kedgä'kätpatzi jojmorambä äj' nwirun'jindam / ngobigbatzi äj' dzokoyjin tumdumäbä tämbu”) (Sánchez, 2013, p. 39). espirituales de la casa común, donde nace y crece la palabra-plegaria que sabe hablar con la Madre Tierra (o Nasakobajk) (p. 43), porque conoce el lenguaje secreto de las fuerzas y los seres de la naturaleza. De esa forma, la poeta va nombrando la vida del pueblo campesino en las figuras del sembrador, de los danzantes y los músicos (el pitero, el tamborero), de los oracionistas o rezadores que ofrendan la palabra, "don [...] revelado en sueños" (Sánchez, 2013, p. 47), del pulsador o médico, ${ }^{13}$ del nigromante, del hechicero, adivino o contador de días, y hasta del brujo (p. 59).

Una vez que la palabra poética nos ha hecho ingresar en el mundo ore, y que el poema ha emprendido de esa manera la reparación del ser zoque, ha devuelto la palabra y los nombres que reconstituyen el cuerpo de su pueblo; una vez que ha hilvanado en la dulzura de su poesía la restitución del sentido, la revalorización epistémica y simbólica de sus prácticas y saberes, Mikeas Sánchez vuelve a mirar a la niña, a la mujer, a la abuela, quienes han sufrido o que sufren. Situada la fuerza de esa ancestralidad, vuelto a ese origen, el último apartado del libro,

13 Se trata del médico tradicional en la cultura zoque, que entre los mestizos también recibe el nombre de "pulsador" (j'ilol, en maya), dado que para tratar al paciente le toman el pulso, dirigiéndose de esa forma a la sangre, que le responderá con un diagnóstico. La sangre dará su mensaje, la yema de sus dedos expertos oirá sobre los temores personales, las desavenencias conyugales, el rencor de los vecinos o el enojo de Dios, de los santos o de los dueños del mundo espiritual que puede estar aquejando al paciente. Oraciones en idioma zoque pronunciadas en voz baja y que muy rápidamente van marcando la ceremonia de toma del pulso. También los médicos tzeltales diagnostican de esta manera, para poder sacar el mal, llamar al alma perdida o medicinar los cuerpos y las casas (puesto que, en estas culturas, el sitio donde habitan las personas igualmente posee un espíritu que interacciona con los de sus moradores). Véase, al respecto, el estudio de Thomas (1974, pp. 105-106). 
"Mojk'jäyä", valoriza y legitima, así, el ser mujer y portadora de la palabra zoque:

Soy mujer / y celebro cada pliegue de mi cuerpo $[\ldots]$ donde navegan mis dudas y mis esperanzas / [...] donde aprisiono los secretos de mi estirpe / y todas las palabras de los ore'pät $t^{14}$ están en mi boca / y toda la sabiduría de las ore'yomo $^{15}$ están en mi saliva (Sánchez, 2013, p. 71).

Desde esa gratitud, desde esa reconciliación con el origen (con la lengua), la voz poética toma la palabra para hablar en nombre de las caídas, de las acalladas, de las violentadas, como un modo de empoderarlas, o también: de devolverles la palabra, mostrando una vez más la importancia y la necesidad de defender (y hablar) el propio idioma.

Las lenguas nunca dejan de hablarse por razones lingüísticas, sino por razones políticas que encubren propósitos de dominación, de explotación. La traducción tiene aquí, entonces, esta función política y ética de restitución; no se trata de una apertura a la alteridad, sino de una apertura a la anterioridad — al origen, entendido como deriva, como horizonte y como suelo- y a la lengua - comprendida como territorio y como cuerpo, como memoria de un diálogo con la trascendencia-. La traducción permanece, entonces, atenta a este juego del significar, donde los nombres hacen sentido y abren también el mundo que significan, para sentar posición y pronunciarse.

\section{La traducción como puente entre culturas, como tránsito entre violencias}

La tentativa de Mikeas Sánchez significa un diálogo entre las orillas de una antigua y una

14 Hombre zoque (Nota de la autora). 15 Mujer zoque (Nota de la autora). nueva palabra, entre las enseñanzas de los antiguos y las realidades de la sociedad zoque contemporánea, pero asimismo traza un puente entre su cultura y la cultura de Estado. En esos pasajes, la traducción - al igual que la poesía - trabaja para renombrar el lugar de la mujer herida y violentada, para revitalizar el cuerpo de la lengua negada, desvalorizada. Violencias y dominaciones que muestran la forma en que una y otra fueron tanto silenciadas como normativizadas y disciplinadas, y con ello, designadas y definidas por el decir (el horizonte de significación y la intención) del otro - con nombres no propios, con parámetros y paradigmas que las amenazan, las minimizan o las niegan-. De ese modo, se pone en escena la violencia simbólica que se ejercita en el dominio del sentido.

El texto bilingüe, como puente, cruza esa opresión enraizada en el cuerpo de la palabra y en el lugar de la traducción. En cuanto acto de recuperación de la lengua, la traducción debe desmontar esa doble posición de inferioridad discursiva, en el texto y en la cultura: como indígena, la herida de haber sido nombrada en español; como mujer, la de ser nombrada por dispositivos machistas que legitiman modos de deseo, desprecio y posesión.

Así, en Mojk'jäyä Mokaya hay un nivel simbólico que obra para reconstruir la herencia zoque, en la cual las mujeres tienen un valor hermoso y fundamental de creación, protección y palabra. En la tradición zoque no son textos, ni discursos, ni autoras las que respaldan la experiencia de un feminismo. Existe un universo espiritual (y un panteón) femenino que protege y resguarda la existencia, que facilita y propicia la vida; hay una casa de mujeres donde la palabra se fortalece, donde circula, donde se han creado estrategias y redes contra las diversas formas de dominación, y se han construido lazos de amor y sabiduría para vivir 
de manera legítima que viven en la oralidad, transmitiéndose de madres a hijas. En este marco, Sánchez traza una analogía recurrente entre las mujeres y las dueñas espirituales de la naturaleza, protectoras y prodigadoras de la vida zoque, que se conocen en esa tradición.

Es justamente en el re-conocimiento de ese origen donde reside, para la autora, la condición de posibilidad para recuperar el poder y la dignidad lesionados, amenazados. En tal dirección, la figura más importante del libro, que reaparece como faro a lo largo del texto y que, como se recordará, da nombre al primer poema - aquel que se propuso pensar como una suerte de prólogo- es Oko'chuwe, madre espiritual que teje la trama de la vida, considerada como "la abuela de todos" (Sánchez, 2013, p. 7):

\begin{abstract}
Abuela / Oko'chuwe / anciana temible / mujer antigua / conocedora del bien y del mal / Madre del placer y del dolor / Diosa renegada [...] / la más cantora / la más danzante / la más tambora / Virgen del inframundo / dueña de los animales pequeños / protectora de las bestias feroces / madre de las plantas / hermana de los peces (Sánchez, 2013, pp. 17-18).
\end{abstract}

Recordar el linaje de esta abuela supone, ante todo, recobrar el dominio del canto, de la protección de los otros y las otras, evocar el lugar de una hermandad, situar la importancia vital del conocimiento de las plantas, pero también recuperar la potestad del deseo y el derecho a decidir, conforme a una ética (a saber y a poder posicionarse ante el bien y el mal).

Oko'chuwe (la gran abuela zoque) es esencialmente una de estas palabras intraducibles. Existen otras que aparecen tejiendo el manto lingüístico de las versiones en español de los textos. Se trata, sobre todo, de la lengua del territorio, esos nombres del lugar o de los espí- ritus que lo habitan: $A b u$ (Gran Padre); Sawabät (Señor del Viento); Mä'ä'bät (Señor del Rayo); Toki' ("palabra sagrada del sembrador, sin traducción”, Sánchez, 2013, p. 33); Kujkiki' (Señor de la lluvia); Nasakobajk (Madre Tierra y espíritu protector del mundo); Ipstäjk (uno de los niveles del mundo de los espíritus, literalmente "veinte casas"); Yaxpalangui (ser espiritual del mundo zoque); Tzuan (uno de los niveles del mundo espiritual zoque, un mundo medicinal y divino); Piogbachuwe (la señora del Volcán); Kopajktzoja, entidad femenina cuyo cuerpo se representa sin cabeza (Sánchez, 2013, p. 75); Muxu’kotzäjk (cerro del gato), Teapan (Tabasco), Kokonä (grutas del Coconá); Tzitzungätzujk (volcán Chichonal) o Tzujsnäbajk (Chichón referido al mismo volcán); Jakima'käjtzäjk (Cerro de Jakima); Mobak' (Río Blanco). De esta forma se bosqueja un diagrama de topónimos, o una topología donde se plasman convergencias, continuidades, conectividades, vecindades que definen el mundo zoque, pero que antes son parte de su caudal hermenéutico y epistemológico que aquí solo queda esbozado, presentado, sugerido.

En ese sentido, estos nombres no deben considerarse en términos mitológicos (como si fueran personificaciones literarias o metáforas del mundo natural), sino que en ellos insiste el profundo diálogo que el pueblo ore mantiene desde antiguo con las fuerzas sutiles que conoce como parte de la existencia, y esas palabras son las que le permiten establecer un intercambio de armonía con el territorio que lo sustenta y que habita. Por tal motivo, no es menor que en el poema en castellano permanezcan con su nombre ore, ya que de ese modo se visibiliza la presencia del mundo zoque en el territorio y del territorio en la lengua. Dan cuenta, por tanto, de la comprensión ore de la vida, en función de una intimidad con la naturaleza y con los espíritus que moran o rigen 
en ella, proximidad que implica efectivamente lazos afectivos y de familia.

Esos términos intraducibles son, entonces, el sustrato intraducible de la visión de mundo, de la experiencia zoque del mundo, y construyen una red de sentido que sostiene otras palabras intraducibles, como Mokaya, Mojk'jäyä, o como ore'pät y ore'yomo (hombre y mujer ore respectivamente, palabras que encuentran lo común, la unidad, justamente en la lengua, en el hablar ore y en su visión de mundo). "Intraducible" quiere decir aquí - como ya se dijo - aquello que tiene que ser pensado como problema en la lengua de la traducción.

En este marco, la praxis de traducción, y más precisamente de autotraducción, asume el bilingüismo del texto para inscribirlo en una visión complementaria propia del mundo indígena; interpela esas categorías tradicionales de la traducción definidas por la transparencia de lo comunicable y por la jerarquía e identidad de los conceptos que han marcado la escisión original/traducción, y propone claves para una traductología indígena y feminista, que reconozca también su propia heterogeneidad, polifonía y plurimorfismo.

\section{La poesía y la traducción como formas de reapropiación de la voz de las mujeres}

Una vez que ha situado estas reivindicaciones en el orden de la cultura y de la lengua, el libro construye finalmente una trama que se teje entre mujeres, donde se dejan ver dolorosos signos de la violencia machista: violencia tanto hacia la mujer como hacia la tierra - portadora de vida, entraña de las generaciones-. Entonces, el texto cimienta un origen, que cruza, como un mismo hálito, el corazón de la mujer zoque que toma la voz poética, soplo que la une y hermana, en ese acto, a otras mu- jeres que la atraviesan: desde la niña a la mujer (ore'yomo), desde la madre (mama'koroya) a la abuela (dzu'mama'koroya), hasta la anciana del mundo espiritual (oko'chuwe).

Así, la flor del maíz, la mujer entendida en términos culturales (Mojk'jäyä) exclama: "Me nombro y hablo por todas las niñas maltratadas" (Sánchez, 2013, p. 75); "Me nombro y hablo por todas las muchachas violadas" (p. 78); "Hablo de mi madre" (p. 81); "Hablo de mi abuela" (p. 84); "Hablo también por todas las vírgenes y rameras" (p. 87) que esperaron la muerte, que guardaron el odio. "Me nombro y hablo por todas las mujeres” (p. 89).

Al mismo tiempo, al nombrarse en ore, el poema da la palabra a quienes sufren el silencio, sienten y duelen el silencio de la lengua minorizada. Al nombrarse como mujer que celebra su sexo, sus caderas, sus pechos, que glorifica su alma (cf. Sánchez, 2013, p. 101), el poema otorga la palabra a quienes no la tienen (y se vuelve solidaria con aquellas al decir nosotras). Hablar de y hablar por esas otras que están en mí; hablar de ellas y por ellas, porque en ellas estoy yo; hablar de mí para hablar con ellas. En esa voz se hilvana la memoria y la voz colectiva (feminista) de esas mujeres, tal como la piensa Mikeas en su libro. Del mismo modo, se escribe en español a la luz del ore; pero también para que el ore entre en la literatura contemporánea, adquiera visibilidad para la lengua del otro, para el monolingüismo del Estado.

Esa voz poética le indica, asimismo, un camino a la teoría de la traducción, señalando un principio para pensar la relación entre textos, contra aquellas jerarquizaciones tradicionales, contra las teorías que conciben la lengua solo en términos de comunicabilidad y mensaje. De esta forma, en el libro aparece el deseo como resistencia. El amor (y la poesía, pero 
también la traducción) como un modo de poner el cuerpo por el otro, por la(s) otra(s): de sublimar, reparar, sanar con la palabra. Esta última se comprende, entonces, como capacidad de hacerse cuerpo en el sufrimiento de otra y de darle a quien está partida una soberanía en la lengua.

Finalmente, si el yo poético recupera la plenitud de su autoestima, alaba la existencia, siente gozo y da gracias por esta, más allá de todas las heridas y todos los errores — "Bendigo a mi padre y a mi madre por haberme engendrado" (Sánchez, 2013, p. 95), "Bendigo el día de mi nacimiento" (p. 94), y el de mi muerte, "Bendigo también mis funerales" (p. 97)-, al mismo tiempo exige: "que nadie más me nombre" (p. 103). Esta afirmación supone un gesto ético y político, a la vez que es un elogio de la traducción por sobre la anulación de las lenguas. La traducción no tiene que nombrar al otro, sino devolverle la palabra. Resistirse a ser nombrada es resistirse a la univocidad del sentido, a la omnipotencia del español como lengua de Estado. Es exigir que la traducción no violente el cuerpo de la lengua, no anule sus diferencias, no las desprecie, no las reduzca a una mitología. Contra la univocidad, se exige el derecho a la diferencia, a la propia lengua.

\section{A modo de cierre}

Walter Benjamin proponía pensar la traducción mediante la analogía con una vasija que se parte en pedazos y que es necesario reconstruir; se trataba, para él, de volver a unir los pedazos de una lengua partida, de reparar, con un pegamento invisible, los fragmentos partidos del sentido (Benjamin, 1971, p. 139). Esa imagen recuerda el arte del kintsugi japonés, arte de la reparación, gracias al cual lo débil se hace bello y fuerte, mostrando, incluso, la belleza de las cicatrices.
Hay algo de este gesto en Mikeas Sánchez cuando pide que nadie más sea medida del gusto, que nadie más se erija en juez de las formas, en dueño de los nombres, en patrón de las lenguas, o administrador de las traducciones y las experiencias. En el último poema, escribe:

No quiero que nadie más me nombre $[\ldots]$ / que nadie más diga si le gustan mis caderas/ o el tamaño de los pechos / Porque mi alma es inmortal / lo mismo que la ceiba y los volcanes / lo mismo que la soledad y el silencio / y mi eternidad no tiene medida / como no tienen medida el abismo ni la muerte (Sánchez, 2013, p. 102).

Se trata de salir del disciplinamiento de la lengua patriarcal y colonial, inscribiéndose en lo abierto del sentido, en la fuerza de las imágenes poéticas, en la singularidad y la individuación de la experiencia y de la lengua.

Las lenguas indígenas, la lengua de las mujeres - la que habla sus saberes, sus pensamientos, la que nombra sus mundos, sus cuerpos, sus anhelos- están doblemente partidas; la traducción debe, entonces, atender a este procedimiento de reparación que la poeta zoque pone en escena en su libro, resarciendo los fragmentos de la cultura, advirtiendo lo que se dice en los silencios, en las violencias, restituyendo la palabra a lo callado, a lo negado, dándose al sentido de lo comunitario - concibiendo un nosotros y un nosotras entre los textos-; finalmente, reparando las heridas, alojando la belleza, la gracia, la potencia de la otra lengua, sin imponerle un significado, pero tampoco reduciéndola a un significante.

En la intemperie que se abre a lo posible, a lo infinito, en esa apertura que no permite que ningún logos se imponga como único o como hegemónico, en la vacilación de las palabras, 
en lo intraducible que expresa un resto que siempre vuelve a ser pensado, se hace posible la recuperación de los territorios de sentido, de la experiencia del nombre y de sus límites. La traducción tiene allí una tarea enorme: la de reconocer la dimensión conocedora de la palabra poética, de los modos de decir, de las metáforas; debe atender y guardar el punto en que el significante no se borra ante el significado, pero la experiencia no se ahoga en lo significante. Lo que se piensa entre lenguas, entre culturas, permite así resarcir los pedazos, reunirlos.

\section{Referencias}

Agamben, G. (2004). Infancia e historia. (S. Mattoni, Trad.). Adriana Hidalgo editora.

Ancalao, L. (2004). Küme Miawmi. Andas bien. Edición de la autora.

Barthès, R. (1993). El placer del texto. Seguido por La lección inaugural (N. Rosa, Trad.). Siglo XXI.

Benjamin, W. (1971). La tarea del traductor. En Angelus Novus (H. Murena, Trad.). Edhasa.

Berman, A. (1999). La traduction et la lettre ou l'auberge du lointain. Éd. du Seuil.

Carballo, M. (2012, septiembre 24). Mikeas Sánchez, poeta zoque, con Mardonio Cabarballo, en Tkio TV, Rompeviento [Video]. YouTube. https://www.youtube.com/ watch?v=4AQ31L0QzUE

Carrasco, I. (2000). Poesía mapuche intercultural. Anales de Literatura Chilena, 1(1), 195-214. http://letras.uc.cl/LETRAS/ html/6_publicaciones/pdf_revistas/anales/a1_13.pdf

Cassin, B. (2019). Elogio de la traducción (I. Agoff, Trad.). El cuenco de plata.

Castro, O., y Spoturno, M. L. (2020). Feminismos y traducción: apuntes conceptuales y metodológicos para una traductología feminista transnacional. Mutatis Mutan- dis. Revista Latinoamericana de Traducción, 13(1): 11-44. https://doi.org/10.17533/ udea.mut.v13n1a02

De Lotbinière-Harwood, S. (1991). Re-belle et infidèle: La traduction comme pratique de réécriture au féminine/The body bilingual: Translation as a rewriting in the feminine. Éditions du Remue-ménage.

Derrida, J. (1985). Des tours de Babel. En J. Graham (Ed.), Difference in translation (pp. 165-248). Cornell University Press.

Estrada, A. (directora). (2003). Tierra de mujeres [Documental. DVD PAL - 57 min.]. México.

Millán, M. (sept-dic, 2009). Revistas y políticas de traducción del feminismo mexicano contemporáneo. Revista Estudos Feministas, 17(3): 819-846. https://doi.org/10.1590/ S0104-026X2009000300011

Moraña, M. (2013). Prólogo. En A. Cornejo-Polar, Escribir en el aire (pp. vii-xiii). CELACP.

Percia, V. (2017). Sur la notion d'original dans la traduction poétique. En A. Tomiche (Ed.), Le comparatisme comme approche critique. Traduction et transferts / Translation and transfers (Tomo 4, pp. 311-320). Classiques Garnier. https://doi.org/10.15122/isbn.978-2-406-06533-3.p.0311.

Perednik, J. S. (2012). Ensayos sobre traducción. Descierto.

Rivera Cusicanqui, S. (2018). Un mundo ch'ixi es posible. Ensayos desde un presente en crisis. Tinta Limón.

Sánchez, M. (2006). Maka mujsi tumä jama / Y sabrás un día. Consejo Estatal para la Cultura y las Artes.

Sánchez, M. (2011). Äj' ngujkomo / Desde mi médula. Colección Astrolabio.

Sánchez, M. (2012a). Kobikyajubä'jaye / Selección poética. Consejo Nacional para la Cultura y las Artes. 
Sánchez, M. (2012b). Mumure' tä' yäjktambä / Todos somos cimarrones. Indómita Editores.

Sánchez, M. (2013). Mojk'jäyä Mokaya. Pluralia (Voces nuevas de raiz antigua).
Thomas, N. (1974). Envidia, brujería y organización ceremonial: un pueblo zoque. sep, Ediciones Caballito. 